Case Report

\section{COVID-19 related rhabdomyolysis}

\section{Alejandro Munoz-Martinez¹, Maham Akbar Waheed ${ }^{1}$, Kenar D Jhaveri ${ }^{2}$ and Geurys Rojas-Marte ${ }^{3,4 *}$}

\author{
${ }^{1}$ Department of Internal Medicine, Maimonides Medical Center, Brooklyn, NY, USA \\ 2Division of Kidney Diseases and Hypertension, Donald and Barbara Zucker School of Medicine at \\ Hof-stra/Northwell, Northwell Health, Great Neck, New York, USA \\ ${ }^{3}$ Department of Cardiology, Maimonides Medical Center, Brooklyn, NY, USA \\ ${ }^{4}$ Department of Cardiology, Donald, and Barbara Zucker School of Medicine at Hofstra/Northwell, \\ Staten Island, NY, USA
}

\section{Introduction}

A novel coronavirus known as Severe Acute Respiratory Syndrome Coronavirus 2 (SARS-CoV-2) with a high rate of human-to-human transmission has emerged, resulting in a worldwide public health crisis of catastrophic proportions. Common initial symptoms of Coronavirus Disease 2019 (COVID-19) include fever, cough, fatigue, myalgia, and shortness of breath. Complications include acute respiratory distress syndrome (ARDS), acute cardiac injury, acute kidney injury, and secondary infections [1,2]. There have been reports of patients infected with COVID-19 who either presented with muscle pain and rhabdomyolysis or developed muscle damage as a late complication during hospitalization [3-8].

In this article, we report the case of a patient presenting with COVID-19 disease and acute kidney injury secondary to rhabdomyolysis. Further, we review the reported cases of COVID-19 related rhabdomyolysis and discuss the possible mechanisms and its management.

\section{Case description}

An 89-year-old Caucasian male was brought to the emergency department by his family for shortness of breath and fever. Symptoms began 10 days earlier with cough, fever, generalized fatigue, and difficulty breathing. The patient developed diarrhea 3 days before presentation. His past medical history was significant for hypertension, coronary artery disease, and heart failure with preserved ejection fraction. His medications included aspirin, candesartan, rosuvastatin, carvedilol, and amlodipine. He was treated with oral doxycycline and later was switched to intravenous ceftriaxone and oral azithromycin prior to admission. There was no history of alcohol.

On arrival, his respiratory rate was 28 breaths/minute; heart rate 90 beats/minute; temperature 98.2 degrees

\begin{abstract}
More Information
*Address for Correspondence: Geurys Rojas-Marte, M.D. Assistant Professor of Cardiology, Donald and Barbara Zucker School of Medicine at Hosftra/Northwell, Department of Cardiology, Maimonides Medical Center, 4802 10th Ave, Brooklyn, NY, USA, Tel: (718) 283-7662; Email: gromart005@gmail.com

Submitted: 22 September 2020

Approved: 19 October 2020

Published: 20 October 2020

How to cite this article: Munoz-Martinez A, Waheed MA, Jhaveri KD, Rojas-Marte G. COVID-19 related rhabdomyolysis. J Clini Nephrol. 2020; 4: 065-069.

DOI: 10.29328/journal.jcn.1001061

Copyright: (c) 2020 Munoz-Martinez A, et al. This is an open access article distributed under the Creative Commons Attribution License, which permits unrestricted use, distribution, and reproduction in any medium, provided the original work is properly cited.

\section{A) Check for updates OPEn ACCEss}

Fahrenheit, and the oxygen saturation was 98 percent on 3 liters/minute of oxygen via nasal cannula. On physical examination, his lungs revealed clear air entry with no wheezing, rhonchi, or crackles; heart sounds were regular without murmurs; his abdomen was soft with normal bowel sounds; he had no pedal edema, blood work was remarkable for creatine phosphokinase (CPK) at 2751 units per liters (U/L) (Table 1). Serum myoglobin level was higher than $4000 \mathrm{U} / \mathrm{L}$, lactate dehydrogenase (LDH) was $805 \mathrm{U} / \mathrm{L}$. His serum creatinine was 2 milligrams per deciliter $(\mathrm{mg} / \mathrm{dl})$ on admission and peaked at $2.5 \mathrm{mg} / \mathrm{dl}$ on hospital day 4 . The serum ferritin was 1401 nanograms per milliliters $(\mathrm{ng} / \mathrm{ml})$, C reactive protein (CRP) was $5.785 \mathrm{mg} / \mathrm{dl}$. We did not check for uric acid level or urine myoglobin; however, his urine was turbid and positive for hemoglobin with 0-2 red blood cells per high power field (HPF). Urine protein was $100 \mathrm{mg} /$ dl with no white blood cells and occasional epithelial cells; there were fine granular casts (5-10). A real-time reverse transcriptase PCR analysis of a nasopharyngeal swab was positive for SARS COV-2 infection. His CPK peaked at 13025 on hospital day 8. Initial potassium level was 3.8 MMOL/L, serum sodium $139 \mathrm{MMOL} / \mathrm{L}$, serum chloride was 110 $\mathrm{MMOL} / \mathrm{L}$, magnesium level was 2.1 MMOL/L and phosphorus level was $3.9 \mathrm{MMOL} / \mathrm{L}$.

\section{Management}

The patient was treated with cautious intravenous 
hydration with a mixture of sodium bicarbonate and $5 \%$ dextrose in water, and supplemental oxygen via nasal cannula. Electrolytes imbalances were corrected accordingly. Other medications included aspirin, vitamin C, Zinc, amlodipine, carvedilol and apixaban for deep venous thrombosis prophylaxis. Rosuvastatin was held on admission and he did not receive hydroxychloroquine. He was discharged home on hospital day 12; his CPK level was in a downtrend $(6361 \mathrm{U} / \mathrm{L})$; and the serum creatinine was 1.3 $\mathrm{mg} / \mathrm{dl}$.

\section{Discussion}

Rhabdomyolysis is a potentially life-threatening condition that develops as a result of skeletal muscle damage from various etiologies. Patients with rhabdomyolysis usually present with myalgias, fatigue, dark urine due to myoglobinuria, electrolyte abnormalities and acute kidney injury (AKI). Since COVID-19 disease can present with similar symptoms, it can be difficult to distinguish between these two conditions based on clinical grounds alone. The presentation of rhabdomyolysis can be insidious, especially in the elderly.

Table 1: Trend in biochemical markers during patient 5 hospitalization

\begin{tabular}{|c|c|c|c|c|c|c|c|c|c|c|c|c|}
\hline Parameter $\quad$ Hospital day & Day 1 & Day 2 & Day 3 & Day 4 & Day 5 & Day 6 & Day 7 & Day 8 & Day 9 & Day 10 & Day 11 & Day 12 \\
\hline CPK (IU/L) & 2751 & 2701 & 2502 & 1623 & 2128 & 4938 & 12342 & 13025 & 12491 & 10008 & 6902 & 6361 \\
\hline CRP (mg/dl) & 5.78 & 6.66 & 5.811 & $*$ & $*$ & * & $*$ & * & $*$ & $*$ & $*$ & * \\
\hline Ferritin $(\mathrm{Ng} / \mathrm{ml})$ & 1401 & 1348.7 & 1331.2 & $*$ & * & * & * & $*$ & $*$ & * & * & * \\
\hline Creatinine (mg/dl) & 2 & 2.1 & 2.3 & 2.5 & 2.4 & 2.3 & 2.1 & 2 & 1.9 & 1.6 & 1.4 & 1.3 \\
\hline Potassium level (MMOL/L) & 3.4 & 3.8 & 3.4 & 3.6 & 3.3 & 3.1 & 3.5 & 3.4 & 3.3 & 3.1 & 3.4 & 3.6 \\
\hline Phosphorus level (Mg/DL) & $*$ & $*$ & 3.9 & 3.7 & 3.3 & 2.9 & 2.8 & 3.0 & 2.9 & $*$ & $*$ & * \\
\hline
\end{tabular}

Table 2: Clinical characteristics of patients reported to date with COVID - 19 associated rhabdomyolysis

\begin{tabular}{|c|c|c|c|c|c|c|c|c|c|c|c|}
\hline $\begin{array}{l}\text { Characteristic } \\
\text { Author }\end{array}$ & Age & Sex & $\begin{array}{l}\text { COVID } \\
\text { severity }\end{array}$ & Onset & $\begin{array}{l}\text { Presentatio } \\
\mathbf{n}\end{array}$ & $\begin{array}{l}\text { Possible } \\
\text { trauma }\end{array}$ & $\begin{array}{l}\text { Statin } \\
\text { use }\end{array}$ & $\begin{array}{l}\text { P e a k } \\
\text { CPK }\end{array}$ & $\begin{array}{l}\text { Creat**}^{* *} \\
(\mathrm{mg} / \mathrm{dl})\end{array}$ & $\begin{array}{l}\text { Treatment } \\
\text { rhabdomyolysis }\end{array} \quad$ for & Outcome \\
\hline Our case & 89 & M & $\begin{array}{l}\mathrm{Mild} \text {. } \\
\text { moderat } \\
\mathrm{e}\end{array}$ & Early & $\begin{array}{l}\text { Generalized } \\
\text { weakness }\end{array}$ & No & Yes & 13025 & 2.5 & IV fluids/bicarb"** & Discharged alive \\
\hline $\begin{array}{l}\text { Suwanwongse } \\
\mathrm{K} .^{3}\end{array}$ & 88 & M & $\begin{array}{l}\mathrm{Mild} \text {. } \\
\text { moderat } \\
\mathrm{e}\end{array}$ & Early & $\begin{array}{l}\text { Bilateral } \\
\mathrm{th} \mathrm{i} \mathrm{g} \mathrm{h} \\
\text { weakness }\end{array}$ & Yes & Yes & 13581 & 1.1 & IV fluids & Discharged alive \\
\hline Chan K. ${ }^{4}$ & 75 & $\mathrm{~F}$ & Severe & Early & Weakness & No & No & 2767 & 1.2 & IV fluids & Discharged alive \\
\hline Chan K. ${ }^{4}$ & 71 & M & Severe & Early & $\begin{array}{l}\mathrm{L} \quad \mathrm{e} g \\
\text { twitching; } \\
\text { weakness }\end{array}$ & No & No & 1859 & 0.9 & IV fluids/hemodialysis & Discharged alive \\
\hline Zhang $Q^{5}$. & 38 & M & $\begin{array}{l}\mathrm{Mild} \text { - } \\
\text { moderat } \\
\mathrm{e}\end{array}$ & Early & $\begin{array}{l}\text { Severe } \\
\text { myalgia/ } \\
\text { back pain }\end{array}$ & No & No & 42670 & 0.9 & IV fluids & Discharged alive \\
\hline Gefen A. ${ }^{6}$ & 16 & M & $\begin{array}{l}\text { Mild- } \\
\text { moderat } \\
\mathrm{e}\end{array}$ & Early & $\begin{array}{l}\text { Myalgi a } \\
\text { dark urine }\end{array}$ & No & No & 427656 & 0.68 & IV fluids/bicarb & Discharged alive \\
\hline Jin and Tong ${ }^{7}$ & 60 & M & $\begin{array}{l}\mathrm{Mild} \text {. } \\
\text { moderat } \\
\mathrm{e}\end{array}$ & Late & $\underset{\text { weakness }}{\mathrm{L}} \mathrm{e} \mathrm{g}$ & No & No & 11842 & Normal* & IV fluids/bicarb & Discharged alive \\
\hline Uysal BB. ${ }^{8}$ & 60 & M & Severe & Early & $\begin{array}{l}\text { Myalgia; } \\
\text { Fatigue }\end{array}$ & No & No & 4267 & 0.91 & IV fluids/bicarb & Discharged alive \\
\hline Sharma et al ${ }^{19}$ & 60 & M & Severe & Early & $\begin{array}{l}A c u \text { t e } \\
k i d n \text { e y } \\
\text { injury }\end{array}$ & No & No & $>90,000$ & 13.1 & $\begin{array}{l}\text { Kidney biopsy confirmed } \\
\text { myoglobin cast } \\
\text { nephropathy } \\
\text { Needed dialysis }\end{array}$ & Died \\
\hline
\end{tabular}


CPK levels should be obtained and are vital in diagnosing suspicious cases that otherwise would be missed due to the atypical nature of the presenting symptoms [9]. Urine analysis is also useful when suspecting rhabdomyolysis.

Possible causes of rhabdomyolysis include trauma, autoimmune disorders, medications, substance abuse, seizures, and infections [9]. Bacterial infections including Legionella, Streptococcus pneumoniae, Salmonella species, Staphylococcus aureus, among others have been described as causes of rhabdomyolysis. [10] Although more frequent in children, viral infections have also been reported to cause rhabdomyolysis in adults [6,11-13].

Multiple viral agents have been implicated in the development of rhabdomyolysis, including the Human Immunodeficiency Virus (HIV), influenza virus, enteroviruses, Epstein-Barr virus (EBV), cytomegalovirus (CMV), Herpes simplex virus, and adenovirus. [10-15] Influenza virus is, by far, the most studied and the most frequently described etiology of viral-associated rhabdomyolysis [12]. Previous publications have suggested the association of the Severe Acute Respiratory Syndrome -SARS- (Non-COVID SARS) with rhabdomyolysis[16-18].

There have been several reports of rhabdomyolysis occurring in patients infected with SARS-CoV-2 [3-8]. These cases (Table 2) have been described mostly in middle aged and elderly patients with moderate to severe COVID-19 disease. Not all patients developed AKI despite significant elevation of CPK levels in some of the cases. Electrolyte abnormalities have not been described in these reports. In our patient, potassium and phosphorus levels were not elevated.

The exact mechanism by which COVID-19 induces rhabdomyolysis is not fully understood. There is consensus that it likely follows the general principles and mechanisms that have been described for other viruses. These include direct viral invasion leading to muscle destruction, a robust immune response to the virus that results in a "cytokine storm", causing damage to muscle tissues, and direct muscle cell destruction by circulating viral toxins $[9,11,12]$. It has been proposed that SARS-CoV-1 associated rhabdomyolysis was due to cytokine storm based on the presence of elevated inflammatory markers found in muscle biopsies of patients infected with the virus $[16,17]$.

While described separately, these events are largely interrelated and should be viewed as part of the same mechanism. Such inter-connected processes can lead to the destruction of muscle cells and spillage of their internal components into the circulation. This in turn can cause AKI, which is mediated by myoglobin build-up in the renal tubules and subsequent development of acute tubular necrosis as a form of pigment nephropathy [9]. It is important to recognize that the current understanding of the pathophysiology of viral-induced rhabdomyolysis comes from in-vitro and observational studies, mainly in COVID-19 disease during Influenza outbreaks $[14,15]$. These hypotheses, while plausible, still require more research before they can be fully accepted. A recent case series by Sharma et al. showed various kidney biopsy findings associated with COVID-19; one of the cases reported was COVID-19 associated rhabdomyolysis leading to pigment nephropathy-related tubular damage [19].

Interestingly, the use of hydroxychloroquine could also contribute to the development of late onset rhabdomyolysis in patients affected by COVID-19 disease [20]. Thus, while it is important to recognize the signs of rhabdomyolysis, it is advisable to avoid using hydroxychloroquine in such patients as it can worsen this condition and its efficacy for treating COVID-19 disease is questionable. Hydroxychloroquine could also cause hemolysis which can lead to hemoglobinassociated kidney injury that can mimic myoglobin-induced kidney injury on kidney biopsy.

In our case, the patient presented to the hospital approximately 10 days after the onset of symptoms. An alternative explanation for the rhabdomyolysis in our report and others is the prolonged periods of bedrest and immobility in convalescent elderly patients along with dehydration. Our patient denied any trauma, seizures, or substance abuse. He was taking rosuvastatin, however, this was held on admission and CPK level peaked on hospital day $8^{\text {th }}$.

Patients affected with rhabdomyolysis should receive aggressive fluid administration to prevent AKI. This must be done with caution, especially in the elderly population where the coexistence of heart failure is more common. Monitoring of serial serum creatinine and CPK levels as well as strict control of intake and output are key in the management of these patients $[16,17,22]$. Treating rhabdomyolysis in elderly patients infected with COVID-19 is even more challenging. Liberal strategies of fluid administration have shown to worsen oxygenation in previous studies of patient with ARDS independent of the cause [23].

Intravenous sodium bicarbonate is often used for alkalization of urine. The strategy we use is $130 \mathrm{meq} / \mathrm{L}$ of sodium bicarbonate (3 ampules) mixed with 1 liter of $5 \%$ dextrose in water and infuse at $200 \mathrm{ml} /$ hour via a separate intravenous line. The rate is adjusted to achieve a urine $\mathrm{PH}$ of $>6.5$. This has been postulated to decrease the breakdown of myoglobin into nephrotoxic metabolites and decrease crystallization of uric acid. This must be done with caution to avoid hypokalemia, hypocalcemia, volume overload and PH shifts $[24,25]$. Some authors do not support the use of sodium bicarbonate, especially if the patient has good urine output [26-28]. The alkalinization of urine could increase the risk of intra-tubular deposition of calcium-phosphate in the setting of rhabdomyolysis-induced hyper-phosphatemia. 
In patients with clinically relevant hyperkalemia (based on electrocardiographic findings) or with values greater than 6.5 mmol per liter; oliguria (less than $0.5 \mathrm{~mL}$ of urine per kilogram per hour for 12 hours); anuria; volume overload or resistant metabolic acidosis $(\mathrm{pH}<7.1)$, renal replacement therapy should be considered for urgent removal of myoglobin from renal tubules. [31] In our case, we administered intravenous fluids while monitoring strict urine output, respiratory rate, and oxygen requirements. We monitored serial serum creatinine and CPK levels.

In the most aggressive forms of rhabdomyolysis, especially if not treated appropriately, severe complications could occur. Early complications of rhabdomyolysis include electrolyte disturbances, typically hyperkalemia and hypocalcemia; these can in turn lead to cardiac arrhythmias and cardiac arrest. Late complications include worsening AKI, disseminated intravascular coagulation (DIC) and compartment syndrome, which may occur early or late due to direct muscle injury (more commonly in cases related to trauma) $[29,30]$.

Our case has several limitations. First, our patient was not tested for other viral infections. However, he presented in May when the influenza season is almost over. Second, the patient was taking a statin prior to admission. Although, drug-induced rhabdomyolysis could be an alternative explanation, this is unlikely given that the statin was stopped on admission and the CPK peak occurred on hospital day $8^{\text {th }}$. Third, the patient's urine level was not tested for myoglobin, however, the urinalysis was positive for hemoglobin, with 0-2 RBCs/HPF; this is characteristic of rhabdomyolysis.

\section{Conclusion}

Rhabdomyolysis is a potentially life-threatening condition that can present at any time during COVID-19 infection, posing an additional challenge to the management of an already complex disease. There should be a high level of clinical suspicion for rhabdomyolysis when treating patients with COVID-19 disease, especially in the presence of significant muscle pain, AKI, and discolored urine. If overlooked, the consequences could be devastating. Early laboratory monitoring with serial serum $\mathrm{CPK}$, myoglobin and serum creatinine are key to the diagnosis; uric acid level and urine myoglobin can also be considered. The mainstay of therapy in these patients relies on aggressive intravenous fluid administration; this should be done with caution in elderly patients who might be at risk of developing heart failure exacerbation. Urine alkalinization could be considered but this is controversial. In patients with severe AKI as well as resistant hyperkalemia it is important to consider urgent hemodialysis for rapid clearance of myoglobin from renal tubules as well as correction of electrolyte abnormalities. It is advised to refrain from using hydroxychloroquine in such patients as it could lead to worsening of rhabdomyolysis or development of late-onset disease.

\section{References}

1. Huang $C$, Wang $Y, L i X$, et al. Clinical features of patients infected with 2019 novel coronavirus in Wuhan, China. Lancet. 2020; 395: 497-506. PubMed: https://pubmed.ncbi.nlm.nih.gov/31986264/

2. Berlin DA, Gulick RM, Martinez F. Severe Covid-19. NEJM. 2020; 10.1056/NEJMcp2009575

PubMed: https://pubmed.ncbi.nlm.nih.gov/32412710/

3. Suwanwongse K, Shabarek N. Rhabdomyolysis as a Presentation of 2019 Novel Coronavirus Disease. Cureus. 12: e7561.

PubMed: https://www.ncbi.nlm.nih.gov/pmc/articles/PMC7202588/

4. Chan KH, Farouji I, Hanoud AA, Slim J. Weakness and elevated creatinine kinase as the initial presentation of coronavirus disease 2019. The Ame J Emergency Med. 2020; 38: 1548. e1-1548.e3. PubMed: https://www.ncbi.nlm.nih.gov/pmc/articles/PMC7211689/

5. Zhang Q, Shan KS, Minalyan A, O'Sullivan C, Nace T. A Rare Presentation of Coronavirus Disease 2019 (COVID-19) Induced Viral Myositis With Subsequent Rhabdomyolysis. Cureus. 2020; 12: e8074. PubMed: https://www.ncbi.nlm.nih.gov/pmc/articles/PMC7290109/

6. Gefen AM, Palumbo N, Nathan SK, Singer PS, Castellanos-Reyes LJ, Sethna CB. Pediatric COVID-19-associated rhabdomyolysis: a case report. Pediatr Nephrol. 2020; 1-4. PubMed: https://www.ncbi.nlm.nih.gov/pmc/articles/PMC7244938

7. Jin $\mathrm{M}$, Tong Q. Rhabdomyolysis as Potential Late Complication Associated with COVID-19. Emerging Infectious Diseases. 2020; 26: 1618-1620.

PubMed: https://pubmed.ncbi.nlm.nih.gov/32197060/

8. Uysal BB, Ikitimur $H$, Yavuzer $S$, Islamoglu MS, Cengiz M. A COVID-19 Patient Presenting With Mild Rhabdomyolysis. Am J Trop Med Hyg. 2020; 103: 847-850.

PubMed: https://www.ncbi.nlm.nih.gov/pmc/articles/PMC7410440/

9. Zutt R, van der Kooi AJ, Linthorst GE, Wanders RJ, De Visser M. Rhabdomyolysis: review of the literature. Neuromuscul Disord. 2014; 24: 651-659.

PubMed: https://pubmed.ncbi.nlm.nih.gov/24946698/

10. Singh U, Scheld WM. Infectious etiologies of Rhabdomyolysis: Three Case Reports and Review. Clin Infect Dis. 1996; 22: 642-649. PubMed: https://pubmed.ncbi.nlm.nih.gov/8729203/

11. Singh U, Scheld WM. Infectious etiologies of rhabdomyolysis: three case reports and review. Clin Infect Dis. 1996, 22: 642-649.

PubMed: https://pubmed.ncbi.nlm.nih.gov/8729203/

12. Fadila MF, Wool KJ. Rhabdomyolysis secondary to influenza A infection: a case report and review of the literature. N Am J Med Sci. 2015, 7: 122-124.

PubMed: https://pubmed.ncbi.nIm.nih.gov/25839005/

13. Ayala E, Kagawa FT, Wehner JH, Tam J, Upadhyay D. Rhabdomyolysis associated with 2009 influenza A(H1N1). JAMA. 2009; 302: 1863-1864.

PubMed: https://www.ncbi.nlm.nih.gov/pmc/articles/PMC3459436/

14. Nance JR, Mammen AL. Diagnostic evaluation of rhabdomyolysis. Muscle Nerve. 2015; 51: 793-810.

PubMed: https://pubmed.ncbi.nlm.nih.gov/25678154/

15. Bosch X, Poch E, Grau JM. Rhabdomyolysis and Acute Kidney Injury. N Engl J Med. 2009; 361: 62-72.

PubMed: https://pubmed.ncbi.nlm.nih.gov/19571284/

16. Wu VC, Hsueh PR, Lin WC, et al. Acute renal failure in SARS patients: more than rhabdomyolysis. Nephrology Dialysis Transplantation. 2004; 19: 3180-3182.

PubMed: https://www.ncbi.nlm.nih.gov/pmc/articles/PMC7107801/

17. Chen LL, Hsu CW, Tian YC, Fang JT. Rhabdomyolysis associated with acute renal failure in patients with severe acute respiratory syndrome. Int J Clin Pract. 2005; 59: 1162-1166. PubMed: https://pubmed.ncbi.nlm.nih.gov/16178983/ 
18. Wang JL, Wang JT, Yu CJ, et al. Rhabdomyolysis associated with probable SARS. Am J Med. 2003; 115: 421-422. PubMed: https://pubmed.ncbi.nlm.nih.gov/14553890/

19. Sharma P, Uppal NN, Wanchoo R, Shah HH, Yang Y, et al. COVID-19. Associated Kidney Injury: A Case Series of Kidney Biopsy Findings $\mathrm{J}$ Am Soc Nephrol. 2020; 31: 1948-1958.

PubMed: https://pubmed.ncbi.nIm.nih.gov/32660970/

20. Wen Z, Liang Y, Hao Y, et al. Drug-Induced Rhabdomyolysis Atlas (DIRA) for idiosyncratic adverse drug reaction management. Drug Discovery Today. 2019; 24: 9-15.

PubMed: https://pubmed.ncbi.nlm.nih.gov/29902520/

21. Patel N, Rein JL, Sanchez-Russo L, Winston J, Uribarri J. COVID-19Associated Acute Kidney Injury: A Case Series. Kidney Med. 2020. 2: 668-669.

PubMed: https://www.ncbi.nlm.nih.gov/pmc/articles/PMC7367023/

22. Parekh R, Care DA, Tainter CR. Rhabdomyolysis: advances in diagnosis and treatment. Emerg Med Pract. 2012; 14: 1-15. PubMed: https://pubmed.ncbi.nlm.nih.gov/22497086/

23. The National Heart, Lung, and Blood Institute Acute Respiratory Distress Syndrome (ARDS) Clinical Trials Network. Comparison of Two Fluid-Management Strategies in Acute Lung Injury. N Engl J Med. 2006; 354: 2564-2575.

PubMed: https://pubmed.ncbi.nlm.nih.gov/16714767/

24. Bagley WH, Yang H, Shah KH. Rhabdomyolysis. Int Emergency Med. 2007; 2: 210-218.

PubMed: https://pubmed.ncbi.nlm.nih.gov/17909702/
25. Khan FY. Rhabdomyolysis: a review of the literature. Neth J Med. 2009; 67: 272-283.

PubMed: https://pubmed.ncbi.nlm.nih.gov/19841484/

26. Better OS, Abassi ZA. Early fluid resuscitation in patients with rhabdomyolysis. Nat Rev Nephrol. 2011; 7: 416-422.

PubMed: https://pubmed.ncbi.nlm.nih.gov/21587227

27. Zimmerman JL, Shen MC. Rhabdomyolysis. Chest. 2013; 144: 10581065.

PubMed: https://pubmed.ncbi.nlm.nih.gov/24008958/

28. Khan FY. Rhabdomyolysis: a review of the literature. Neth J Med. 2009; 67: 272-283.

PubMed: https://pubmed.ncbi.nlm.nih.gov/19841484/

29. Chatzizisis YS, Misirli G, Hatzitolios Al, Giannoglou GD. The syndrome of rhabdomyolysis: complications and treatment. European J Internal Med. 2008; 19: 568-574.

PubMed: https://pubmed.ncbi.nlm.nih.gov/19046720/

30. Sauret JM, Marinides G, Wang GK. Rhabdomyolysis. American Family Physician. 2002; 65: 907.

PubMed: https://pubmed.ncbi.nlm.nih.gov/11898964/

31. Maggi G, Quinteros Hinojosa F, Villagran MJ, Guasch Arevalo E, Gilsanz Rodriguez F. Renal replacement therapy in acute kidney failure due to rhabdomyolysis. Case Rep Crit Care. 2012; 2012: 603849.

PubMed: https://pubmed.ncbi.nlm.nih.gov/24826338/ 